\title{
Simulation of Vehicle Movements for Planning Construction Logistics Centres
}

\author{
Fei Ying ${ }^{1}$, Mike O'Sullivan ${ }^{2}$ and Ivo Adan ${ }^{3}$ \\ ${ }^{1}$ Department of Built Environment Engineering, Aucland University of Technology, Auckland, New Zealand \\ ${ }^{2}$ Department of Engineering Science, University of Auckland, Auckland, New Zealand \\ ${ }^{3}$ Department of Industrial Engineering, Eindhoven University of Technology, Eindhoven, The Netherlands \\ fei.ying@aut.ac.nz, michael.osullivan@auckland.ac.nz,i.adan@tue.nl
}

Keywords: Construction Logistics, Simulation.

\begin{abstract}
Materials supply is one of important elements in construction operation and a major factor affecting the quality of construction projects. With materials accounting for $60 \%$ of the on-site cost of a typical construction project, effective management of this vital resource is essential. Logistics processes, being crucial for successful completion of the project, are often entrusted to external professionals specialized in logistic services, such as logistics centres. However, this tendency is yet to be developed in construction. The purpose of this paper is to examine the potential of managing logistics costs by planning construction logistics centres. The planned centres are then evaluated using vehicle movement simulations. The enclosed results from the simulations indicate that using a logistics centre will have reduced waste for the construction project considered. A literature review and case study analysis are employed, with simulation results using Flexsim. The paper emphasizes that creating a logistics centre for a project at its early stages of planning and then designing an integrated logistics service for that project may help find ways of making the overall construction project more effective by improving management of materials.
\end{abstract}

\section{INTRODUCTION}

Lean construction is an attempt to apply lean principals that originate form Toyota Production System (TPS) to construction, aiming at managing and improving construction processes with minimum cost and maximum value by considering customer needs (Gao and Low, 2014). Following years of developing, there have emerged significant studies that have correlated lean principals with construction. Lean construction alters the traditional view of the project as transformation and have changed the way constructors manage the operations (Jorgensen and Emmitt, 2008). Lean tools and techniques come into helping identify and eliminate the waste that adds no value. In practice, Construction Supply Chain Management (CSCM) is one of the systems to implement lean construction philosophy.

CSCM is defined as "the network of facilities and activities that provide customers with economic value to the functions of design development, contract management, service and material procurement, material manufacture and delivery, and facilities management" (Love et al., 2004). The term "logistics", as used in the title of the paper, is related to the term "supply chain". Logistics is defined as "the process of strategically managing the acquisition, movement and storage of materials, parts and finished inventory (and the related information flows) through the organisation and its marketing channels, in such a way that current and future profitability is maximised through the cost-effective fulfilment of orders" (Gattorna and Day, 1993). For the construction industry, logistics comprise planning, organisation, coordination, and control of the materials flow from the procurement of raw materials to the incorporation into the finished building (Agapiou et al., 1998).

Building materials and construction components, along with human resources, are the first and most important requirements for construction. Materials supply is thus a factor affecting the quality of construction projects and the profitability for construction firms. With materials accounting for up to $60 \%$ of the on-site cost of a typical construction project (Song et al., 2005) and between 15 and 30 per cent of urban waste (Formoso et al., 2002), effective 
management of this vital resource is essential. Furthermore, research suggests that improved logistics will attain monetary and schedule savings, reduce material waste, increase productivity and safety (Jang et al., 2003; Poon et al., 2004; Shakantu et al., 2003; Spillane and Oyedele, 2013). Thus, effective construction logistics should provide appropriate trade-offs involving costs and service in the supply chain by integrating materials supply, storage, processing and handling; site infrastructure and equipment location; physical site flow management and information management (Shakantu et al., 2008).

Many industries attempt to integrate logistics processes into logistics chains of suppliers and customers, from obtaining raw material, through manufacturing, distribution and final sale and service to the end-users. Logistic processes, which are crucial for successful completion of the project, are often entrusted to external professionals specialised in logistics services, such as logistics centres (Sobotka and Czarnigowska, 2005). However, in the field of construction, this tendency is to be developed. Moreover, recent research has shown that, in the management of material deliveries, an ad hoc, intuitive approach is often adopted (Spillane and Oyedele, 2017; Ying et al., 2014). Consequently, there appears to be a significant need for an enhanced understanding of transportation in a construction context in order to deliver the full benefits from the adoption of efficient construction logistics. The purpose of this research is to address how the efficiency of construction logistics can be improved by using logistics centres. In order to evaluate the effect of using a logistics centre, we provide a simulation case study that measures logistics waste with and without a logistics centre.

Next section surveys the related literature. It follows by defining the problem environment and the research methodology. The mathematical models and scenario considered are then described. The paper ends with conclusions and further research directions.

\section{LOGISTICS ISSUES IN CONSTRUCTION}

\subsection{Lack of Supply Chain Innovations}

While many industries have experienced performance improvements through supply chain management initiatives, the construction industry is yet to realise these improvements to the same extent.
Several researchers have explained the particular features of the industry that hinder these potential benefits, such as the fragmented structure of the industry (Fadiya et al., 2015), the negative consequence of arm-length relationships (Briscoe and Dainty, 2005), and the lack of trust and commitment among the firms involved in the process (Gadde and Dubois, 2010).

Determining project logistics process requires a wide range of construction project management knowledge, such as knowledge of the building materials market, financing, and managing contractors' approaches to supply. It also demands a deep understanding of the impact of logistics on project efficiency in terms of cost, quality and time. Furthermore, it is of great impact to be aware of logistics costs and their relationship to variables such as batch size, place and time of the delivery, and required storage conditions.

\subsection{On-site and off-Site Logistics}

Efficiency and effectiveness of a construction project heavily depend on the integration between on-site and off-site logistics. However, a lack of planning of materials deliveries and unloading among subcontractors and their site workforce causes significant issues in this interface (Ying et al., 2014). Previous research shows that substantial benefits can be attained through the rearrangement of on-site logistics (Lindén and Josephson, 2013). Off-site logistics refers to supply logistics involving suppliers of building materials.

The aim of logistics customer service is to ensure that construction materials are appropriate and available for construction operations. Thus, service related factors affecting vehicle movements are planning, training, loading and the logistics management strategy. It is widely recognised that the troublesome logistics in the construction industry is influenced by the characteristics of the industry, including the fragmentation of the construction industry supply chain, lack of coordination and communication among actors, inefficient planning both on-site and off-site. From the project managerial perspective, the real-time scheduling of materials planned and keyed to the master plan for material delivery is highly desirable. However, frequently this is unachievable because of many factors, such as inadequate detailed information at the commencement of a contract, and considerable variations during the construction stage. 


\section{RESEARCH METHODOLOGY}

The guiding purpose of this study was to develop a simulation framework for analysis of potential improvements of logistics performance using logistics centres. The focus of the work is to identify achievable benefits through optimising off-site logistics. The studies in this work were carried out as a case study with simulation modelling. The case study described in this paper has been developed from a commercial project hosted by a university. The $\$ 100$ million project consists of a 13 level tower block with a roof top plant room surrounded with lecture theatres and student facilities. The new construction integrates several existing buildings on campus. The construction has three stages: ground works, structure, and fit-out.

Special attention has been paid to the numbers and patterns of vehicle movements, since it was expected that appropriate interventions to improve construction logistics could be identified through analysing these elements. The vehicle movements were recorded by the gates-person on the site. Details such as delivery company name, date, time, truck type, materials, and activities were noted on printed tables.

\subsection{Flexsim}

The simulation case study has been developed in the Flexsim environment. "Flexsim is an object-oriented software environment used to develop, model, simulate, visualize, and monitor dynamic-flow process activities and systems" (Nordgren, 2003). Flexsim models consist of a tree of individual nodes that contain model objects, library objects, commands, and all model information. Within this tree are flowitems which are simple objects that are created to move through the model. Flowitems can represent actual objects, or they can be representative of a more abstract concept.

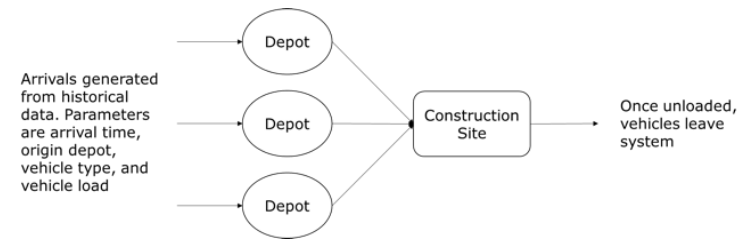

Figure 1: Simulation pathway without a logistics centre.

(a) Simulation pathway without a logistics centre. Vehicles arrive to depots according to historical data (which is also used to determine the vehicle size and load), travel to the construction site, are unloaded according to triangular distributions and leave the system

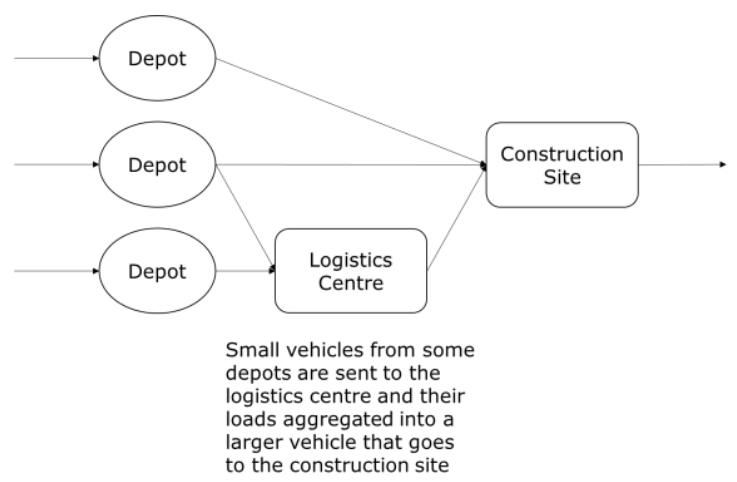

Figure 2: Simulation pathway with a logistics centre.

(b) Simulation pathway with a logistics centre. Vehicles arrive in the same way as without the logistics centre, but now some of the smaller vehicles travel to the logistics centre where their loads are aggregated before being delivered in a larger vehicle to the construction site. Other vehicles go directly to the construction site as before. Some depots dispatch both small and large vehicles, but only the small ones go to the logistics centre

The movement of vehicles within the construction logistics process is depicted in Figure 1, for the scenario with no logistics centre, and Figure 2, for the scenario with a logistics centre, respectively. In the construction logistics model two different flowitems library classes are used. The Box class is used to represent the cargo of a vehicle and the Pallet class is used to represent the vehicle. These classes are used as they already contain the functionality for loading and unloading required for simulating construction logistics. Deliveries are simulated using historical data by creating a delivery vehicle (a Pallet) at a depot and creating the appropriate cargo (a number of Boxes) and combining them together. Note that the arrival time at the depots of the loaded vehicles is calculated from their arrival time on-site less the travel time from the depot to the site. This combined flowitem can have its properties altered, e.g., image type, colour, to enable the simulation's visualisation to be representative of the construction site activities, which is useful for validating the simulation via visual inspection. The delivery flowitem then travels from its origin (e.g., the supplier) to the construction site or (if it is being used) the logistics centre. At the logistics centre smaller vehicles can be unloaded, i.e., the underlying Pallet and Box objects separated, and combined into a larger vehicle, i.e., a new (higher capacity) Pallet is 
combined with the Boxes from multiple (smaller) Pallets, which then travels to the construction site. This way transportation between suppliers, the logistics centre (if it is being used) and the construction site is visible. It is important to set the correct speed between locations to get the desired travel duration.

Once loaded vehicles arrive to the construction site they are unloaded either by hand or using equipment available on-site. In this model there are two cranes that can be used for unloading along with a hoist. If the unloading equipment is already busy, then the vehicle needs to wait in the loading bay for the appropriate equipment or, if the delivery area is full, wait outside the site itself. Once unloaded both vehicles and their load leave the system.

In the model, queues and queuing mechanisms are used to model vehicles waiting to be unloaded. It is possible to change the strategy of queueing from the default of First-in First-Out (FIFO) to investigate priority policies that may streamline deliveries. Once the equipment required to unload a vehicle is available, the vehicle is unloaded with the unloading duration dependent on the type of load, the size of the load, and the equipment being used. The load (the Box objects) are separated from the vehicle (the Pallet) and the vehicle leaves the site. At this point the delivery is complete and box the load and the vehicle are removed from the model.

By experimenting with the use of a logistics centre and policies for unloading deliveries, the simulation model can be utilised to evaluate the effect of a logistics centre and also determine if similar improvements could have been achieved by adopting a less ad hoc approach to managing deliveries.

\section{KEY FINDINGS}

The main aim of this paper is to contribute to the knowledge of setting up logistics centres to improve construction logistics performance. The key findings section of the paper is focused on where to locate the logistics centre and the potential improvements that can be achieved in practice by using this centre. The improvements are measured by simulating vehicle movements to the site and/or the logistics centre and observing the effect on vehicle waiting time on-site.

\subsection{Locating Logistics Centre}

In order to determine the best location for the logistics centre, data from vehicle deliveries were used to visualise the depots where each vehicle began its delivery from. Google API was used for this visualisation and travel durations between the depots, the logistics centre, and the construction site were also acquired via Google API. The depot address of each subcontractor and material supplier were first translated into longitude and latitude, visualised on a background map, then used in the simulation model for deliveries. The result of the visualisation, as shown in Figure 3, can then be used to evaluate potential locations for the logistics centre at which delivery loads of vehicles could be merged. The size of the circles in Figure 1 represents the amount of deliveries that originated from this particular company, hence its depot. The exception is the large grey circle which the construction site itself. It is obvious that a large percentage of deliveries originated from certain suburbs. The simulation model depicted in Figure 3 located the logistics centre in one of these suburb, Penrose, and evaluated the subsequent performance improvement. The logistics centre location is shown as a small black rectangle neat the centre of Figure 3.

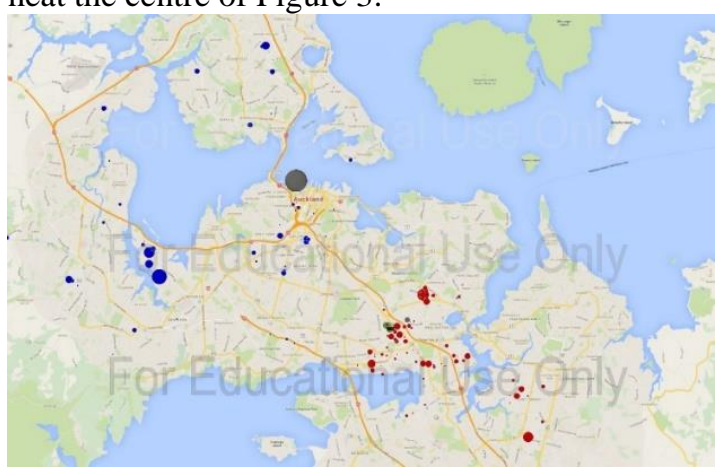

Figure 3: Flexsim visualisation of companies.

\subsection{Simulations of Vehicle Merging}

One scenario simulated in this case study merges all small vehicle loads, within the Penrose region (shown in red in Figure 3), at the Penrose logistics centre and the delivers the aggregated load of materials to the construction site located in the Auckland CBD. In the simulation model the assumption is that all small vehicles go to the hoist with a mean process time of 30 minutes, while all large vehicles are directed to one of the cranes (with equal probability) with a mean process time of 45 minutes. The process times are modelled using a Triangular distribution with minimum value equal to $2 / 3$ of the mean and maximum value equal to $4 / 3$ of the mean. Hence, there are two symmetric distributions, with the appropriate mean values, for unloading via either a crane or the hoist 
The number of total deliveries occurring during construction is 6889 of which 2256 (33\%) are made by small vehicles. The total deliveries from the Penrose region during construction is $2465(36 \%)$ of which 857 (12\% of total deliveries) are small vehicles. By merging small vehicle deliveries from the Penrose region each day the number of deliveries can be reduced from 857 to 281 , a reduction of $67 \%$. Note, however, that the new deliveries from the Penrose logistics centre will require larger vehicles with more load so that merged vehicles use a crane with a mean process time of 60 minutes.

A comparison of the system with and without the logistics centre is now possible via the Flexsim simulation (running 20 replications for 468 days each). Table 1 shows the number of small vehicle, large vehicle, and merged vehicle deliveries. Table 2 shows the expected waiting time (in minutes) for the cranes and the hoist with and without the Penrose logistics centre. Note that the waiting time for the hoist demonstrates a clear difference and is almost halved when the Penrose logistics centre is used. However, the waiting time for the crane also demonstrates a clear difference with the waiting time being slightly worse when the Penrose logistics centre is used.

Although waiting time is one key measure of waste, a better comparison between the systems is that of total unloading time on-site. Aggregating the loads of small vehicles from the Penrose region onto larger vehicles means that the cranes are used more (281 more times) and for longer each time (mean process time of 60 minutes), but there are far less small vehicle deliveries on-site. While the average waiting time (for a crane or the hoist) is the time vehicles waste while idle, the total time spent unloading on-site measures the "busy-ness" caused by deliveries. If aggregating loads at a logistics centre causes more total on-site busy-ness, even if it reduces the average waiting time per vehicle, then its efficacy is questionable. Table 2 shows that the total time spent unloading on-site is reduced by approximately 18 days over the duration of the construction project. Note that this saving is offset by unloading (and possibly waiting) tie at the logistics centre, but time spent at the logistics centre does not reduce productivity at the construction site so it is not measured.
Table 1: Number of each type of delivery vehicle.

\begin{tabular}{|c|c|c|}
\hline $\begin{array}{c}\text { Delivery } \\
\text { Vehicle } \\
\text { Type }\end{array}$ & $\begin{array}{c}\text { No Logistics } \\
\text { Centre }\end{array}$ & $\begin{array}{c}\text { Penrose } \\
\text { Logistics Centre }\end{array}$ \\
\hline Small & 2256 & $\begin{array}{c}2256-857= \\
1399\end{array}$ \\
\hline Large & $\begin{array}{c}6889-2256= \\
4633\end{array}$ & 4633 \\
\hline Merged & 0 & 281 \\
\hline
\end{tabular}

Table 2: $95 \%$ confidence interval for expected waiting time (minutes).

\begin{tabular}{|c|c|c|}
\hline Measure & $\begin{array}{c}\text { No Logistics } \\
\text { Centre }\end{array}$ & $\begin{array}{c}\text { Penrose } \\
\text { Logistics } \\
\text { Centre }\end{array}$ \\
\hline $\begin{array}{c}\text { Waiting time for } \\
\text { Hoist (mins) }\end{array}$ & {$[29.4,30.1]$} & {$[16.1,16.6]$} \\
\hline $\begin{array}{c}\text { Waiting time for } \\
\text { Crane (mins) }\end{array}$ & {$[41.6,49.3]$} & {$[46.4,49.0]$} \\
\hline $\begin{array}{c}\text { Total on-site } \\
\text { unloading time } \\
\text { (days) }\end{array}$ & {$[191.5,191.7]$} & {$[173.6,173.9]$} \\
\hline
\end{tabular}

\section{CONCLUSIONS}

The simulation confirms that using logistics centres can improve construction logistics performance. Through logistics centres, off-site logistics are consolidated and optimized. This in turn will stimulate the planning of on-site logistics performance. This approach could solve previously observed problems identified in relation to insufficient planning, limited storage capacity, waste in extra material handling, and low delivery reliability.

When the principles of logistics centres are applied, the interface between off-site and on-site logistics could be connected seamlessly. The main findings in relation to reduced waiting time to be unloaded, the number of vehicle movements on-site, and total on-site unloading time are encouraging. This would significantly increase the efficiency of cranes and hoists utilization, which are the most expensive equipment on construction sites.

Future research will investigate the feasibility of establishing logistics centres, especially determining any impediments to implementing this concept in the construction industry. The improvement of construction logistics efficiency will not be realised without commitment that is initiated from within the construction industry and application of logistical expertise. Further research will focus in identifying the financial costs and benefits logistics centres could 
bring to various actors, such as main contractors, subcontractors and material suppliers.

\section{REFERENCES}

Agapiou A, Clausen LE, Flanagan R, et al. (1998) The role of logistics in the materials flow control process. Construction Management and Economics 16: 131137.

Briscoe G and Dainty A. (2005) Construction supply chain integration: an elusive goal? Supply Chain Management: An International Journal 10: 319-326.

Fadiya O, Georgakis P, Chinyio E, et al. (2015) Decisionmaking framework for selecting ICT-based construction logistics systems. Journal of Engineering, Design and Technology 13: 260-281.

Formoso CT, Soibelman L, Cesare CD, et al. (2002) Material waste in building industry: main causes and prevention. Journal of Construction Engineering and Management 128: 316-325.

Gadde L-E and Dubois A. (2010) Partnering in the construction industry -- Problems and opportunities. Journal of Purchasing and Supply Management 16: 254-263.

Gao S and Low SP. (2014) Impact of Toyota way implementation on performance of large Chinese construction firms. Journal of Professional Issues in Engineering Education and Practice 140: 1179-1183.

Gattorna J and Day A. (1993) Strategic issues in logistics. International Journal of Physical Distribution and Logistics Management 16: 3-42.

Jang H, Russell JS and Yi JS. (2003) A project manager's level of satisfaction in construction logistics. Canadian Journal of Civil Engineering 30: 1133-1142.

Jorgensen B and Emmitt S. (2008) Lost in transition: the trasfer of lean manufacturing to construction. Engineering, Construction and Architectural Management 15: 383-398.

Lindén S and Josephson P-E. (2013) In-housing or outsourcing on-site materials handling in housing? Journal of Engineering, Design and Technology 11: 90-106.

Love PED, Irani Z and Edwards D. (2004) A seamless supply chain management model for construction. Supply Chain Management: An International Journal 9: 43-56.

Nordgren WB. (2003) Flexible simulation (Flexsim) software: Flexsim simulation environment. 35th conference on Winter simulation: driving innovation. New Orleans, LA, USA, 197-200.

Poon CS, Yu ATW, Wong SW, et al. (2004) Management of construction waste in public housing projects in Hong Kong. Construction Management and Economics 22: 675-689.

Shakantu W, Muya M, Tookey J, et al. (2008) Flow modelling of construction site materials and waste logistics: A case study from Cape Town, South Africa. Engineering, Construction and Architectural Management 15: 423-439.
Shakantu WM, Tookey JE and Bowen PA. (2003) The hidden cost of transportation of construction materials: An overview. Journal of Engineering, Design and Technology 1: 103-118.

Sobotka A and Czarnigowska A. (2005) Analysis of supply system models for planning construction project logistics. Journal of Civil Engineering and Management XI: 73-82.

Song J, Haas CT, Caldas Ch, et al. (2005) Locating materials on construction site using proximity techniques. ASCE Construction Research Congress Proceedings of the Construction Research Congress. San Diego, CA.

Spillane JP and Oyedele LO. (2013) Strategies for effective management and safety in confined site construction. Australasian Journal of Construction Economics and Building 13: 50-64.

Spillane JP and Oyedele LO. (2017) Effective material lobistics in urban construction sites: a structural equation model. Construction Innovation 17: 406-428.

Ying F, Tookey J and Roberti J. (2014) Addressing effective construction logistics through the lens of vehicle movements. Engineering, Construction and Architectural Management 21. 